\title{
Article \\ Effect of Sulfate-Reducing Bacteria (SRB) on the Corrosion of Buried Pipe Steel in Acidic Soil Solution
}

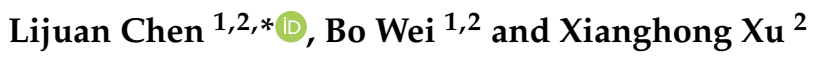 \\ 1 State Key Laboratory of Chemistry and Utilization of Carbon Based Energy Resources, Xinjiang University, \\ Urumqi 830046, China; wb001@xju.edu.cn \\ 2 School of Chemical Engineering, Xinjiang University, Urumqi 830046, China; xuxianghong@xju.edu.cn \\ * Correspondence: chenlijuan@xju.edu.cn
}

Citation: Chen, L.; Wei, B.; Xu, X. Effect of Sulfate-Reducing Bacteria (SRB) on the Corrosion of Buried Pipe Steel in Acidic Soil Solution. Coatings 2021, 11, 625. https://doi.org/ 10.3390 /coatings11060625

Academic Editor: Paweł Nowak

Received: 22 April 2021

Accepted: 20 May 2021

Published: 24 May 2021

Publisher's Note: MDPI stays neutral with regard to jurisdictional claims in published maps and institutional affiliations.

Copyright: (c) 2021 by the authors. Licensee MDPI, Basel, Switzerland. This article is an open access article distributed under the terms and conditions of the Creative Commons Attribution (CC BY) license (https:// creativecommons.org/licenses/by/ $4.0 /)$.

\begin{abstract}
The influence of sulfate-reducing bacteria (SRB) on the corrosion behaviors of X80 pipeline steel was investigated in a soil environment by electrochemical techniques and surface analysis. It was found that SRB grew well in the acidic soil environment and further attached to the coupon surface, resulting in microbiologically influenced corrosion (MIC) of the steel. The corrosion process of X80 steel was significantly affected by the SRB biofilm on the steel surface. Steel corrosion was inhibited by the highly bioactive SRB biofilm at the early stage of the experiment, while SRB can accelerate the corrosion of steel at the later stage of the experiment. The steel surface suffered severe pitting corrosion in the SRB-containing soil solution.
\end{abstract}

Keywords: X80 steel; sulfate-reducing bacteria; biofilm; pitting; EIS

\section{Introduction}

Corrosion has been acknowledged as the largest capital loss in oil/gas industries, leading to various environmental and economic problems and even a fatal threat $[1,2]$. Microbiologically influenced corrosion (MIC) refers to material degradation that is influenced by various microorganisms existing in soil, marine, and industrial environments, which is a serious threat to pipeline integrity [3]. In fact, MIC was also found in other industrial equipment, such as heat exchangers, cooling systems, and storage tanks [4], estimated at about $20 \%$ of the annual corrosion in China [5]. Among several types of microbes responsible for MIC in soils, sulfate-reducing bacteria (SRB) have been identified as the main culprit causing progressive MIC of pipes, further leading to buried pipeline failure [6,7].

SRB can survive over a wide $\mathrm{pH}$ range of $4.0-8.0$, at temperatures of $10-40{ }^{\circ} \mathrm{C}$, and at pressures up to $507 \mathrm{~atm}$, which are active and can be a threat in anaerobic environments [8]. Enhanced corrosion of buried pipeline steel by SRB in soil environments has been reported. Previous research has shown that the corrosion rate of steel increased six times in the presence of SRB compared with that in a sterile solution [9]. Bhat et al. [10] reported that a new pipeline failed due to MIC in only 8 months. Abedi et al. [11] also reported an MIC failure of X52 pipeline in Iran. They demonstrated that the SRB intensified the corrosion of the pipeline steel and the further related stress cracking corrosion (SCC) process. Generally, buried pipelines are usually protected from external corrosion by coatings and cathodic protection (CP), but MIC still happens when the coating is disbonded and the CP current is shielded after a long time of service [12]. Xu et al. [13] reported that SRB corrosion is severe under a disbonded coating in a neutral soil solution. Wei et al. [14] also demonstrated that the corrosion of steel was accelerated by SRB under a disbonded coating in an acidic soil solution. Various mechanisms of SRB corrosion have been proposed, e.g., cathodic depolarization theory (CDT) [15], corrosive metabolites theory (CMT) [16], and direct electron transfer theory (DETT) [17]. It was reported that the activities of SRB enhanced steel corrosion [18]. During the SRB corrosion process, a biofilm layer consisting of SRB 
cells, water, extracellular polymeric substances (EPS), and corrosion products is formed on the coupon, which has an effect on the dissolution of the steel [19]. Videla et al. [20] concluded that a biofilm containing iron sulfide is the main SRB corrosion product, which can accelerate steel corrosion by cathodic depolarization through film spalling or rupture by SRB metabolic actions. Dong et al. [21] also found that SRB biofilms seriously accelerate the corrosion of steel. In addition, one study proposed that SRB can acquire energy by directly harvesting electrons from iron under starvation and severely enhance corrosion [22]. $\mathrm{Xu}$ and $\mathrm{Gu}$ [23] also reported that SRB can utilize electrons released by anodic oxidation as an electron donor under the starvation condition, and that the biofilm is more corrosive against steel. Actually, the corrosion induced by SRB is a complex process, and the mechanism of SRB corrosion is not fully understood [24]. Furthermore, various studies have been carried out in neutral soil simulation solutions. An acidic soil located in southeast China with an average $\mathrm{pH}$ of 3.5-6.0 is distributed in several provinces. A number of oil/gas pipelines operate in this area. It has been found that acidic soils are extremely aggressive towards various metallic materials [25,26]. Yan et al. [27] reported that Fe oxides are enriched in this type of soil, which also stimulate soil corrosion in anaerobic conditions by acting as a cathodic depolarizer. Wei et al. [28] found that the stray current is a key factor leading to severe corrosion of pipeline steel in acidic soils. Thus far, the aggressiveness of acidic soils towards steel has not been fully understood. Can SRB grow in acidic soil environments? Are biotic factors such as SRB also an important factor in accelerating the corrosion of pipeline steel in red soil? However, SRB corrosion in acid soil environments is seldom reported. Therefore, it is necessary to investigate the effects of SRB on the corrosion of steel in acidic soils.

In this work, electrochemical impedance spectroscopy (EIS) combined with scanning electron microscopy (SEM), energy-dispersive spectrometry (EDS) and X-ray photoelectron spectroscopy (XPS) techniques was used to investigate the effect of SRB on the corrosion behavior of X80 steel in acidic soils.

\section{Experimental}

\subsection{Materials and Solutions}

In this work, the material used was API X80 steel pipe, and its composition is given in Table 1. Figure 1 shows the optical microstructure of the specimen after etching with $4 \%$ nital. Pearlite and ferrite are the major constituents, where the ferritic phase appeared white in color and in non-uniform, nonpolygenic shapes, and the pearlite region appeared dark in color. The specimens with dimensions of $10 \mathrm{~mm} \times 10 \mathrm{~mm} \times 3 \mathrm{~mm}$ were embedded in epoxy resin, leaving a working area of $10 \mathrm{~mm} \times 10 \mathrm{~mm}$. The working surface was progressively ground using silicon carbide papers (a series of 120,240,400,600, and 800 grit), followed by degreasing with acetone and dehydration in $100 \%$ ethanol. Before use, all specimens were sanitized using an ultraviolet lamp for $20 \mathrm{~min}$.

Table 1. Chemical composition of X80 steel (wt.\%).

\begin{tabular}{cccccccc}
\hline $\mathbf{C}$ & $\mathbf{M n}$ & $\mathbf{S i}$ & $\mathbf{P}$ & $\mathbf{S}$ & $\mathbf{C r}$ & $\mathbf{N i}$ & $\mathbf{C u}$ \\
\hline 0.07 & 1.82 & 0.19 & 0.007 & 0.023 & 0.026 & 0.17 & 0.02 \\
\hline $\mathbf{A l}$ & $\mathbf{M o}$ & $\mathbf{T i}$ & $\mathbf{N b}$ & $\mathbf{V}$ & $\mathbf{N}$ & $\mathbf{B}$ & $\mathbf{F e}$ \\
\hline 0.028 & 0.23 & 0.012 & 0.056 & 0.002 & 0.004 & 0.0001 & Bal. \\
\hline
\end{tabular}




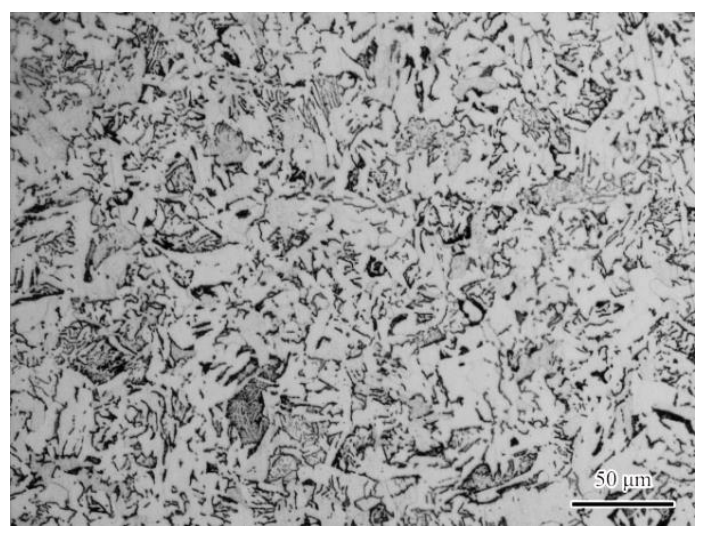

Figure 1. Optical microstructure of API X80 steel used in this work.

Culture media were used to investigate SRB corrosion in most research works. However, soil environments are more complex. Therefore, the test solution in this study was a soil-extracted solution for an acidic soil located in Ying-Tan of Jiang-Xi Province, China. Soils were taken from 1.2 to $1.5 \mathrm{~m}$ underground. The composition of the soil is shown in Table 2. Firstly, the soil and distilled water were mixed in a ratio of 1:1 to obtain a saturated soil liquid. The soil liquids were stirred for $1 \mathrm{~h}$ and then kept stationary for $1 \mathrm{day}$. Finally, the soil-extracted solution was obtained by filtering the supernatant with qualitative filter papers $(0.22 \mu \mathrm{m})$. Before testing, high-purity $\mathrm{N}_{2}$ gas was purged from the test solution for $2 \mathrm{~h}$ to achieve an anaerobic condition, and the gas flow was maintained throughout the test. Prior to use, the soil solution was autoclaved at $121{ }^{\circ} \mathrm{C}$ for $20 \mathrm{~min}$ and stored at $4{ }^{\circ} \mathrm{C}$.

Table 2. Chemical composition of the soil in this work ( $\mathrm{mg} / \mathrm{kg}$ soil).

\begin{tabular}{ccccccccc}
\hline $\mathbf{p H}$ & $\mathrm{Ca}^{2+}$ & $\mathbf{M g}^{2+}$ & $\mathbf{K}^{+}$ & $\mathbf{N a}^{+}$ & $\mathbf{N O}_{3}{ }^{-}$ & $\mathbf{C l}^{-}$ & $\mathbf{S O}_{4}{ }^{2-}$ & $\mathbf{H C O}_{3}{ }^{-}$ \\
\hline 4.5 & 5 & 2 & 4 & 8 & 4 & 9 & 10 & 11 \\
\hline
\end{tabular}

\subsection{SRB Culturing and Inoculation}

The strain of SRB used in this work is Desulfovibrio desulfuricans, which was isolated from soils. The SRB were cultured in API RP-38 medium (g/L) [29]. Before inoculation, the strain was kept in an incubator for $12 \mathrm{~h}$ to activate its biological activity. A 5\% (vol.\%) SRB culturing medium was added to the soil solution to obtain the test solution. Additionally, equal normal sterilized culture medium was added to the soil solution as abiotic control for comparison.

\subsection{Electrochemical Measurements}

Electrochemical impedance spectroscopy (EIS) measurements were carried out using a three-electrode system by an EG\&G PAR 2273 (AMETEK Instruments, Princeton, NJ, USA). The test specimen was used as a working electrode (WE). A saturated calomel electrode (SCE) and a platinum plate served as reference electrode (RE) and counter electrode (CE), respectively. All EIS tests were conducted at the open-circuit potential (OCP) with a sinusoidal alternating amplitude signal of $10 \mathrm{mV}$ over the frequency range from $10^{5}$ to $10^{-2} \mathrm{~Hz}$. The curve fitting was performed with ZSimpWin software (version 3.21). All measurements were conducted at a room temperature of $25 \pm 2{ }^{\circ} \mathrm{C}$, in triplicate.

\subsection{Surface Analysis}

After testing, the specimens were removed from the cell, immersed in a $4 \%(w / w)$ glutaraldehyde solution for $2 \mathrm{~h}$, sequentially dehydrated with alcohol for $5 \mathrm{~min}$ at various concentrations $(25 \%, 50 \%, 75 \%, 95 \%$, and $100 \%(w / w))$, and then dried. SEM (FEI Quanta 450 , Hillsboro, OR, USA) was used to observe corrosion products' morphologies on the 
specimen surface, and the elemental compositions of the products were analyzed via equipped energy-dispersive spectrometry (EDS).

The live/dead cells were characterized by a confocal laser scanning microscope (CLSM, C2 Plus, Nikon, Tokyo, Japan). Before characterization, the specimens were dyed using the Live/Dead ${ }^{\circledR}$ BacLight $^{\mathrm{TM}}$ Bacterial Viability Kit L7012 (Invitrogen, Molecular Probes, Inc., Eugene, OR, USA) in darkness for $20 \mathrm{~min}$.

XPS (ESCALAB250, Thermo VG, Waltham, MA, USA) was performed employing an amonochromatic X-ray source ( $\mathrm{Al} \mathrm{Ka}$ line of $15 \mathrm{kV}$ and $150 \mathrm{~W}$ ) with a pass energy of $50 \mathrm{eV}$ and a step size of $0.1 \mathrm{eV}$, and XPS PEAK software (version 41) was used to fit the curve.

The corrosion products on specimens were removed using a chemical method with a descaling solution, and then the morphologies of corroded specimen surfaces were observed by SEM. The pit depth on the specimen surface was measured by a threedimensional (3D) surface profilometer (MicroXAM, Milpitas, CA, USA). During the process of the measurement, the position of the deepest pits on the specimen surface was located under an optical microscope at $10 \times$ magnification and then zoomed in at $100 \times$ magnification to further measure the depth.

\section{Result}

\subsection{Live/Dead Staining}

During the corrosion process, cells adhered on the surface of the specimens gradually to form an SRB biofilm. Figure 2 shows the SRB biofilm morphologies after live/dead staining under CLSM, where the green and red colors indicate the live and dead cells, respectively. Clearly, it can be seen that the SRB biofilm formed on the entire specimen surface, full of live sessile cells after 14 days in the SRB-containing soil solution, and the number of live cells on the surface is much more than that of dead cells. The biofilm thickness measured is $20 \mu \mathrm{m}$. Additionally, the SRB biofilm observed is sparse, which is mainly attributed to the depletion of nutrients in the solution after 14 days of immersion [12,30].

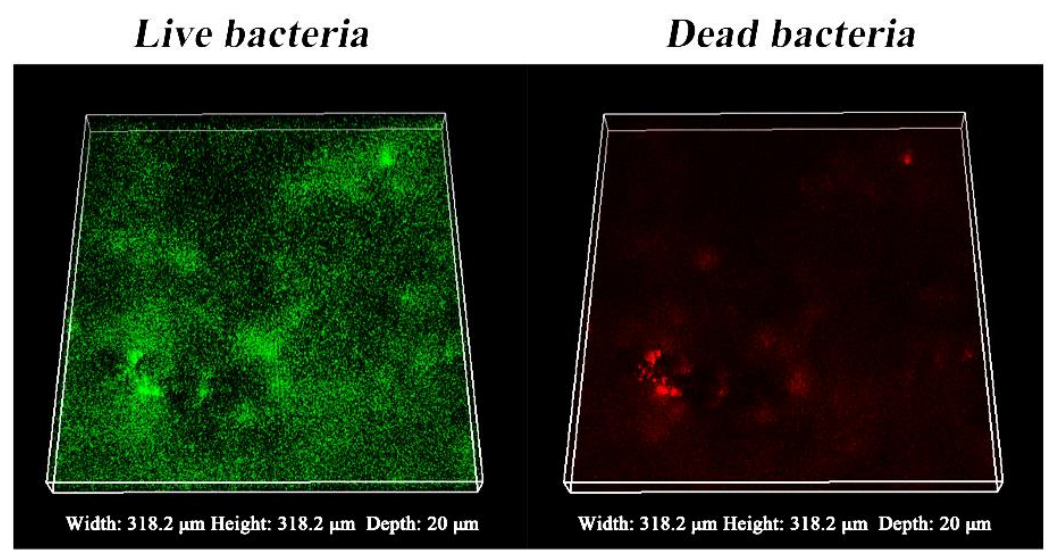

Figure 2. CLSM images of biofilm formed on specimen surface after 14 days of immersion in SRB-inoculated soil solution.

\subsection{Characterization of Corrosion Products on Specimen Surface}

Figure 3 shows the morphologies of the corrosion products formed on the specimen surface in the abiotic and SRB-containing soil solutions after 14 days, and the corresponding EDS analysis results are given in Table 3. In the absence of SRB, some cluster-like products can be observed on the specimen surface. In the presence of SRB, different corrosion morphologies can be observed on the specimen surface. Apparently, mushroom-like corrosion products can be observed on the specimen surface, with a large number of sessile SRB cells presenting a rod shape with a length of 1-4 $\mu \mathrm{m}$ and overlapping with the corrosion products. Additionally, the corresponding EDS analysis results clearly demonstrate that the element of $\mathrm{S}$ is detected, which is related to the SRB activities [31]. The elements $\mathrm{Al}$ and 
Si should be ascribed to the soil solution. Furthermore, the C content (7.41\%) in the abiotic soil solution is much lower than that in the inoculated soil solution (17.53\%), which is due to the fact that the element $C$ is the main element in the SRB biofilm [32].

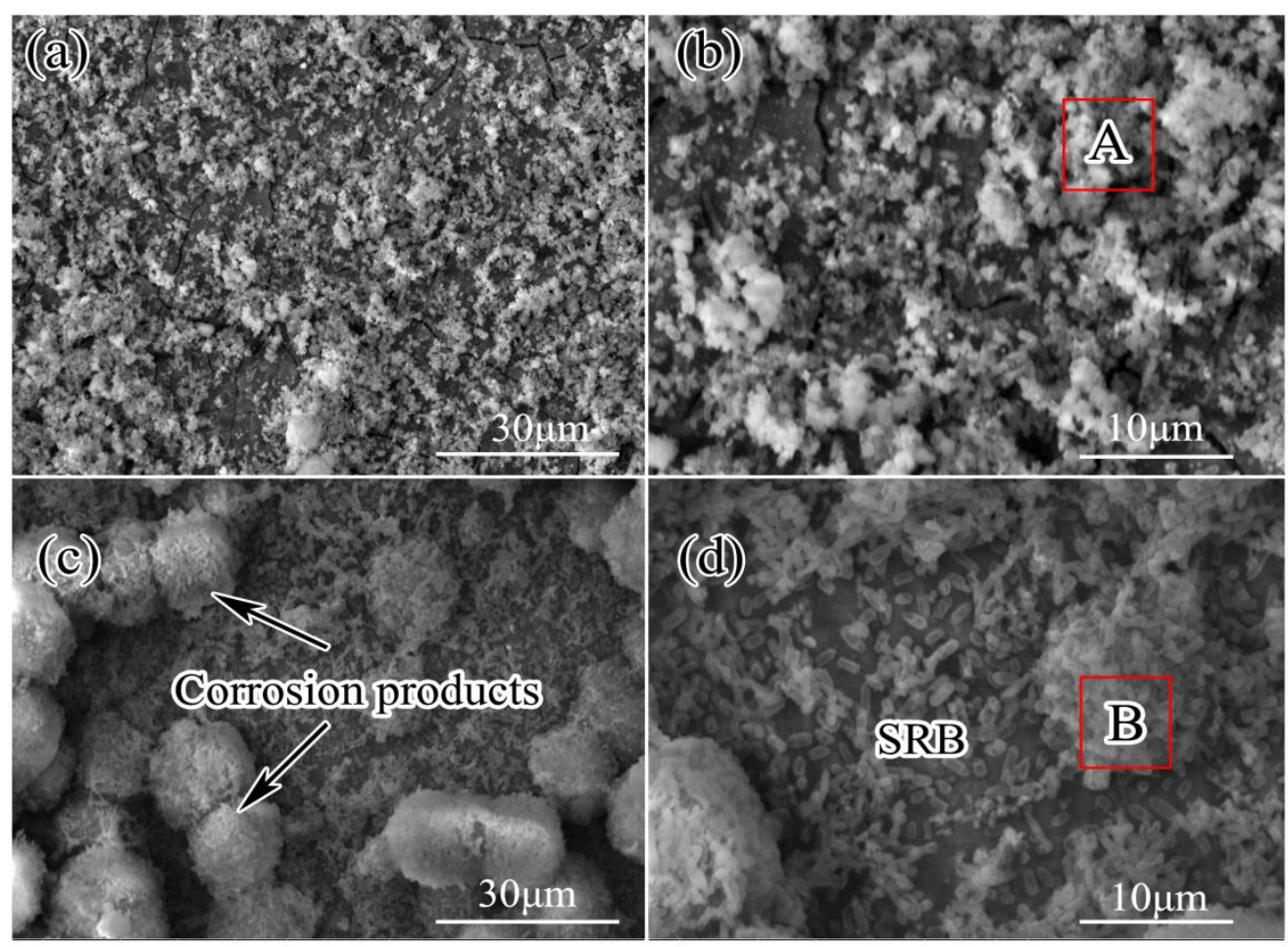

Figure 3. SEM images of the corrosion products on the specimen surface in sterile solution $(\mathbf{a}, \mathbf{b})$ and SRB-containing solution (c,d) after 14 days of immersion.

Table 3. Results of EDS of the corrosion products on the steel surface.

\begin{tabular}{cccccccc}
\hline \multirow{2}{*}{ Positions } & \multicolumn{7}{c}{ Element (wt.\%) } \\
\cline { 2 - 8 } & $\mathbf{C}$ & $\mathbf{O}$ & Al & Si & P & S & Fe \\
\hline A & 7.41 & 23.45 & 0.12 & 0.68 & 6.53 & - & 61.71 \\
B & 17.53 & 26.94 & 0.03 & 0.51 & 13.09 & 1.83 & 40.38 \\
\hline
\end{tabular}

The composition of corrosion products formed on the specimen surface in the SRBcontaining solution was further analyzed by XPS. Figure 4 shows the high-resolution XPS spectra of Fe $2 p$ for the specimen in the SRB-containing soil solution after 14 days. The Fe $2 p$ spectra were curve fitted as $\mathrm{Fe}_{3} \mathrm{O}_{4}(711.4 \mathrm{eV}), \mathrm{FeS}(713.6 \mathrm{eV})$, and $\mathrm{FeOOH}(725.3 \mathrm{eV})[33,34]$, which are the major corrosion products formed on the specimen. Additionally, the XPS results further confirm the existence of sulfides in corrosion products, which is consistent with the EDS results. FeS is the typical metabolic sulfide generated by SRB activities, which can be embedded in an SRB biofilm [14,35,36]. 


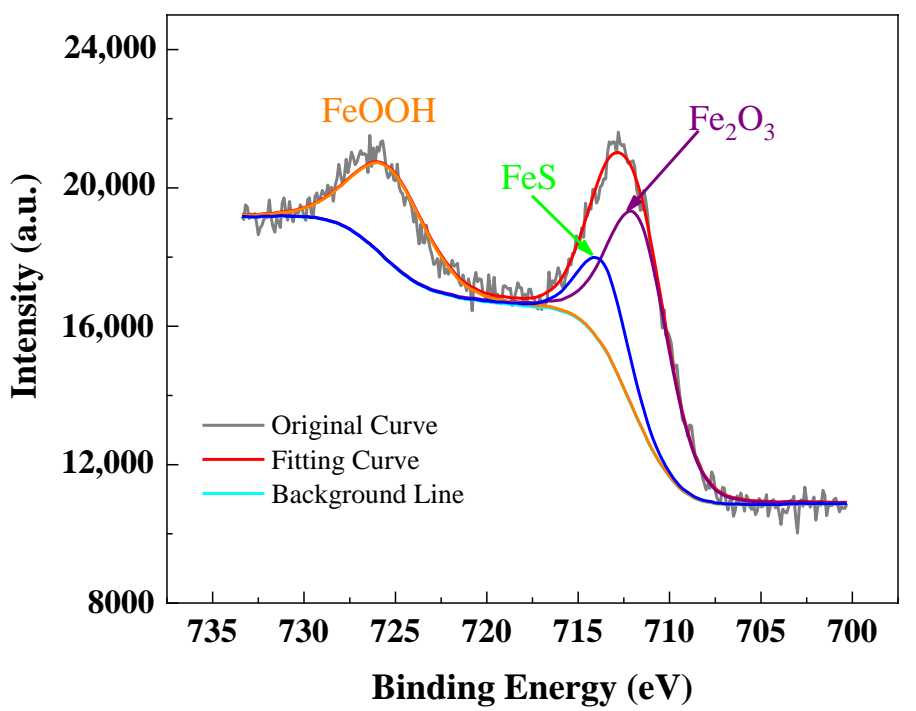

Figure 4. High-resolution XPS spectra of Fe 2p for specimen in the SRB-containing solution after 14 days.

\subsection{Pitting Morphologies}

Figure 5 shows the surface morphologies of the specimen surface after 14 days in the abiotic and SRB-containing soil solutions after the corrosion products were removed. Localized corrosion is observed in the absence and presence of SRB, as shown in Figure 5. It is seen that the surface of the steel in the abiotic condition is relatively flatter with a few localized corrosion pits, while more pit holes can be observed on the specimen surface in the inoculated condition. The amounts and sizes of corrosion pits formed on the specimen surface in the presence of SRB significantly increase, demonstrating the enhanced pitting corrosion. Additionally, some pit holes are connected with each other to form large pitting holes, and the surface of the specimen becomes rougher than that in the abiotic control. The maximum pit morphologies of specimens observed by the 3D surface profilometer are presented in Figure 6. In the absence SRB, the maximum pitting depth on the specimen surface measured is only $2.32 \pm 0.2 \mu \mathrm{m}$. However, the maximum pitting depth on the specimen in the inoculated solution is $6.01 \pm 0.6 \mu \mathrm{m}$, much larger than that in the abiotic solution. The above results clearly suggest that pitting corrosion was considerably enhanced by SRB.
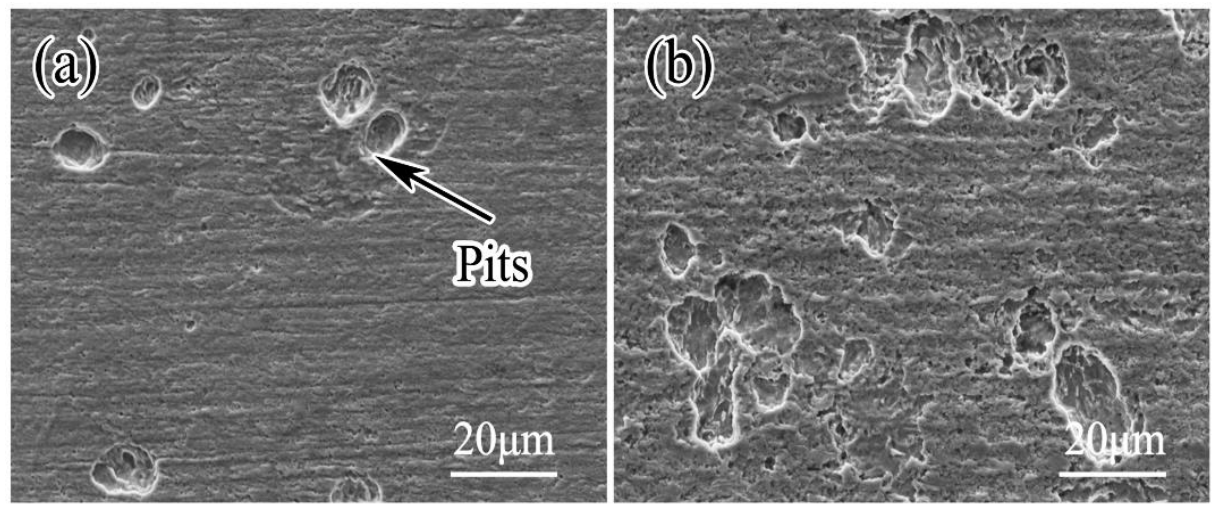

Figure 5. SEM images of specimen surface with corrosion products removed in the abiotic (a) and inoculated solutions (b) after 14 days. 

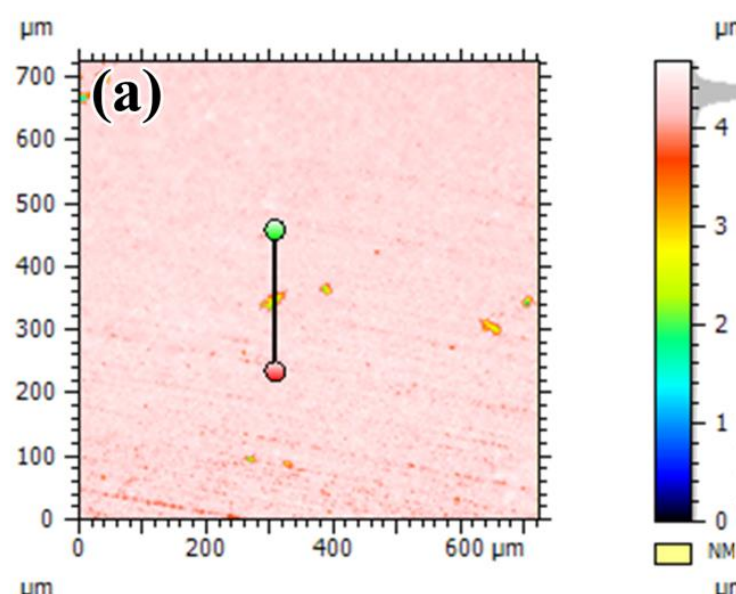

(b)
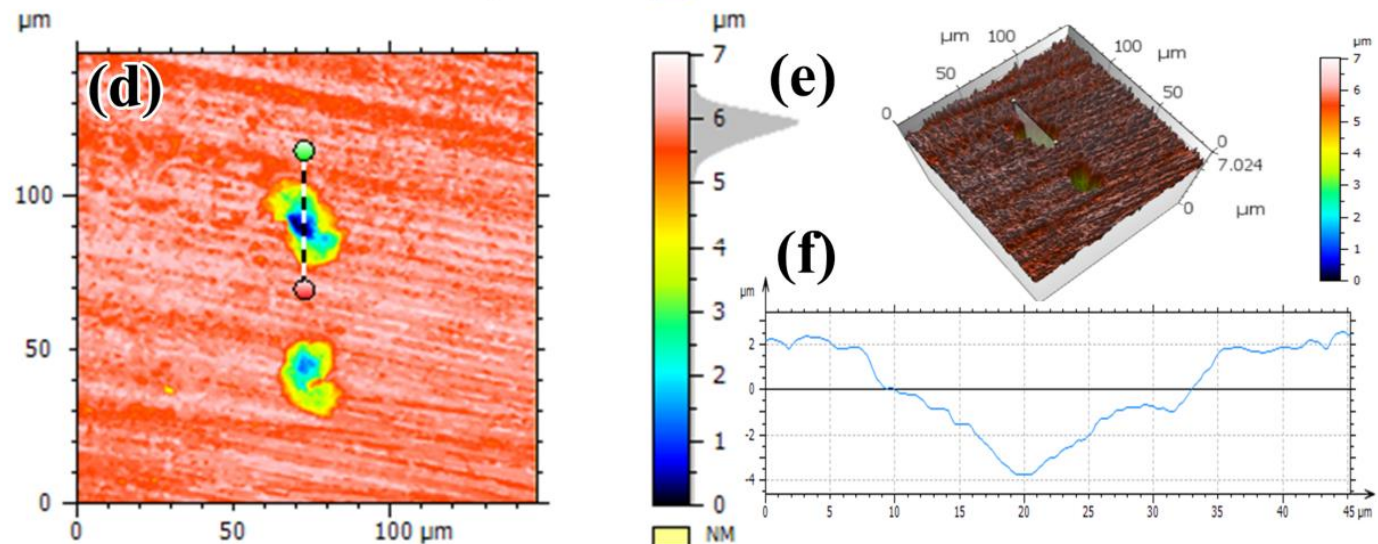

Figure 6. Maximum pit depth measured on specimen in the abiotic (a-c) and inoculated solutions (d-f) after 14 days.

\subsection{OCP Measurements}

The variations in OCP values with time for specimens in the abiotic and inoculated soil solutions are shown in Figure 7. The OCP of the specimen in the abiotic solution shifts in a negative direction at the beginning and then reaches a relatively steady value with time. For the inoculated condition, however, the OCP of the specimen shifts in a positive direction at the beginning and then also reaches a relatively steady value. After 11 days, the OCP of the steel further decreases in both abiotic and inoculated conditions. Additionally, the OCP of the specimen in the presence of SRB is more positive than that in the absence of SRB during the 14 days of immersion, which is mainly due to the fact that a biofilm and corrosion products were formed on the specimen, leading to a more positive potential [14,28]. 


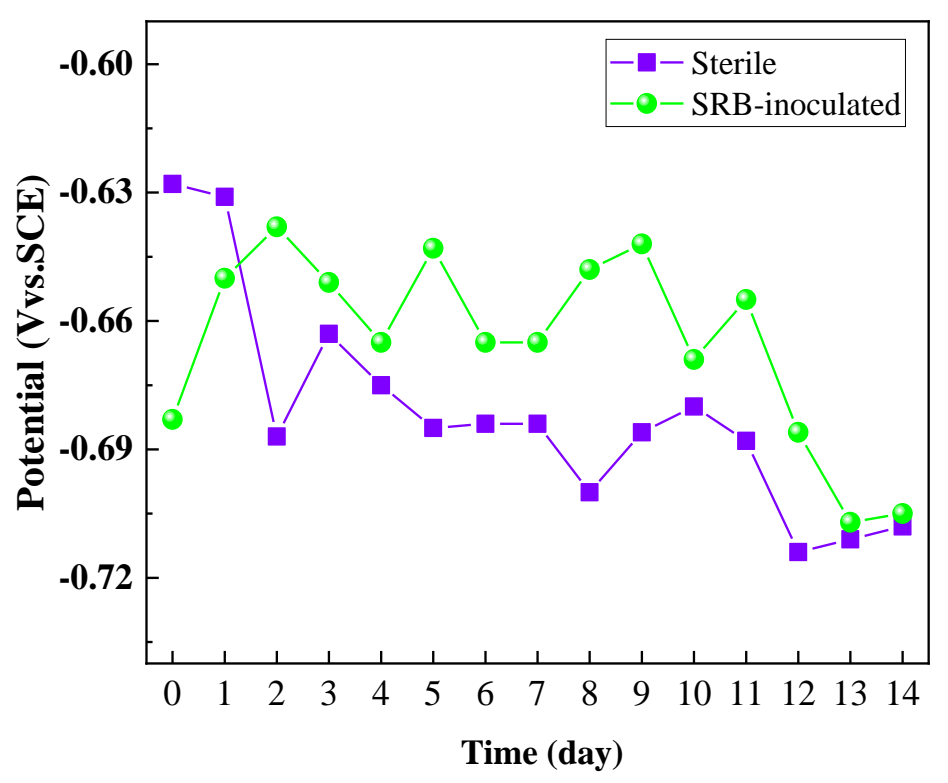

Figure 7. Time dependence of the potential for specimens in the abiotic and inoculated soil solutions over 14 days.

\subsection{EIS Results Analysis}

The Nyquist plots of specimens during 14 days of immersion in the abiotic and inoculated soil solutions are shown in Figure 8. All measured impedance curves (Figure 8a,b) show a semicircle over the whole frequency range, and any diffusion process cannot be identified from the Nyquist plots. As shown in Figure 8a, the size of the semicircle becomes smaller with time in the abiotic solution, which indicates that the electrochemical corrosion process of steel is accelerated with time. For the SRB-inoculated solution, the semicircle size also reduces with time and becomes smaller and smaller during the 14 days of testing. Additionally, it is also seen that the diameters of the semicircles in the SRB-containing solution (Figure 8b) are bigger than those measured in the abiotic solution (Figure 8a) in the first 4 days of testing, which suggests that the corrosion of the steel is suppressed in the presence SRB in the first 4 days of testing. The increased diameters of the semicircle are associated with the corrosion of the steel initially. In the presence of SRB, a thick biofilm layer formed on the steel. The living bacteria have a significant effect on the corrosion process of steel $[37,38]$. After 7 days, the diameters of the semicircle measured in the inoculated solution are smaller than those measured in the abiotic solution, suggesting corrosion is enhanced by SRB. The above results indicate that the SRB activity and metabolite influence the corrosion behavior of the steel, which inhibited the corrosion of the steel in the first 4 days and accelerated it in the rest. 
(a)

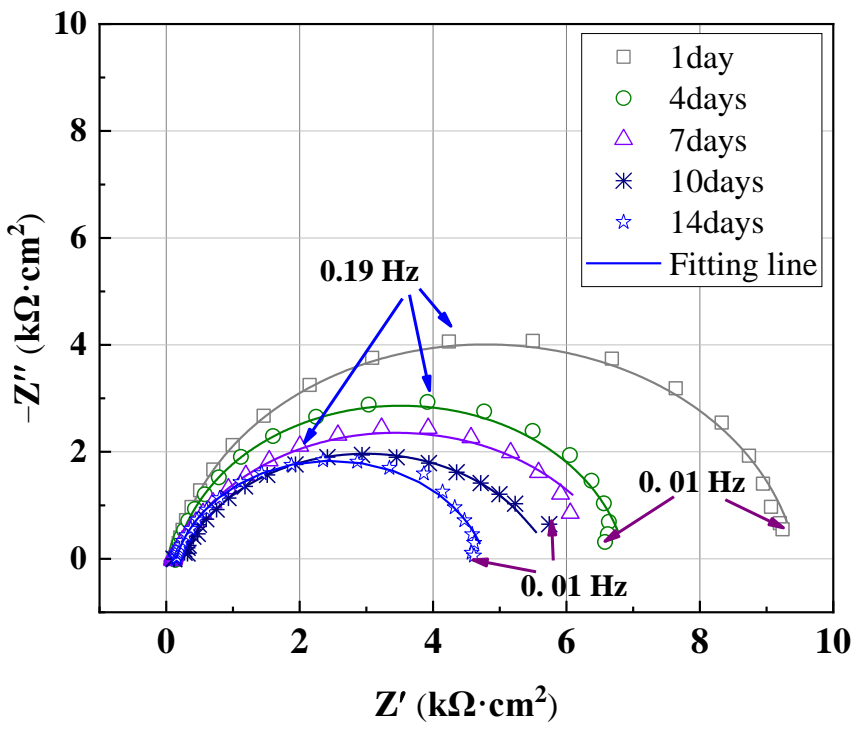

(b)

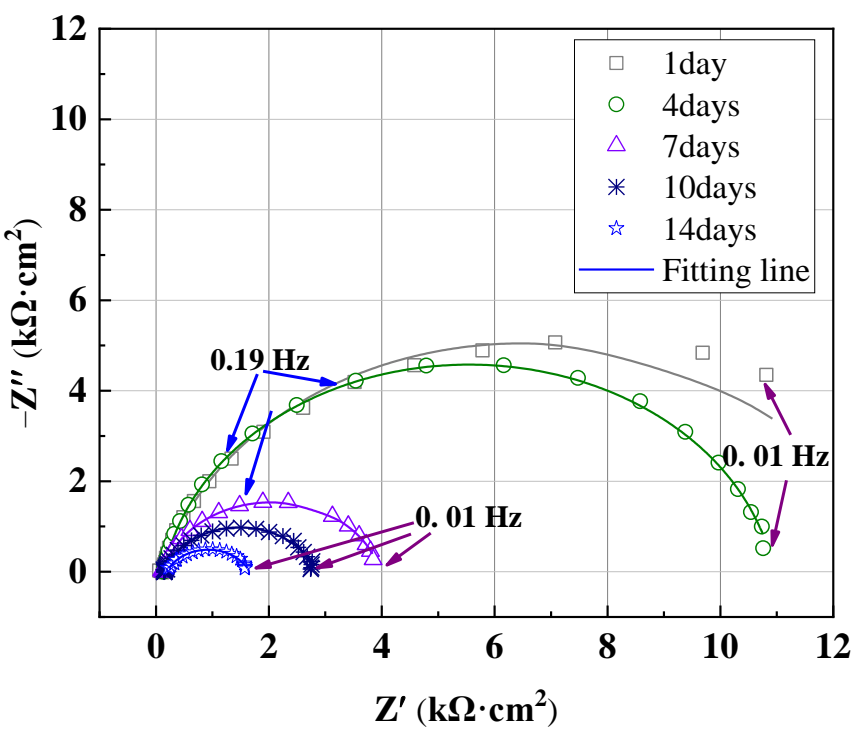

Figure 8. Nyquist plots of specimen in the abiotic (a) and SRB-inoculated soil solutions (b).

An electrical equivalent circuit (EEC) (Figure 9), i.e., $R_{\mathrm{s}}\left(Q_{\mathrm{dl}} R_{\mathrm{ct}}\right)$, was used to analyze the EIS measured results (Figure 8), and the fitted impedance kinetics parameters are listed in Table 4 . In the EEC, $R_{\mathrm{S}}$ and $R_{\mathrm{ct}}$ are the solution resistance and the charge transfer resistance, respectively; $Q_{\mathrm{dl}}$ is the electric double layer capacitance. The impedance of $Q_{\mathrm{dl}}$ is determined by [21]

$$
Z_{\mathrm{Q}}(w)=\frac{1}{Y_{0}(j w)^{-\mathrm{n}}}
$$

where $Z_{\mathrm{Q}}$ is the impedance of $Q_{\mathrm{dl}}, j$ is the imaginary unit, $j^{2}=-1, w$ is the angular frequency, $Y_{0}$ is the CPE parameter, and $n$ is the dispersion coefficient related to the surface inhomogeneity.

A higher $R_{\mathrm{ct}}$ value indicates a lower corrosion rate of the steel [21]. On day 1, the $R_{\text {ct }}$ value of steel in the absence of SRB is $9318 \Omega \cdot \mathrm{cm}^{2}$ and decreases gradually with time. After 14 days, the $R_{\mathrm{ct}}$ of steel reaches the smallest value, $4640 \Omega \cdot \mathrm{cm}^{2}$, which decreases over two times, indicating a higher corrosion rate. In the presence of SRB, the $R_{\mathrm{ct}}$ slightly increases to $13950 \Omega \cdot \mathrm{cm}^{2}$ compared with that in the abiotic condition after $1 \mathrm{~d}$ and then also decreases gradually with time. After 4 days, the $R_{\text {ct }}$ of steel also slightly increases 
compared with that in the abiotic solution. With the time further increasing, however, the $R_{\mathrm{ct}}$ values of steel are much lower than those in the control. The $R_{\mathrm{ct}}$ is the smallest with a value of $1467 \Omega \cdot \mathrm{cm}^{2}$ after 14 days in the inoculated solution, which is over three times smaller than that in the control.

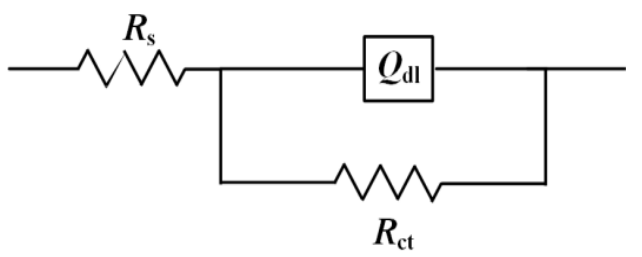

Figure 9. Electrochemical equivalent circuits used to fit the EIS data in this work.

Table 4. Fitted parameters for the Nyquist plots in the abiotic and inoculated solutions.

\begin{tabular}{|c|c|c|c|c|c|c|c|c|}
\hline \multirow{3}{*}{$\begin{array}{l}\text { Time } \\
\text { (day) }\end{array}$} & \multicolumn{4}{|c|}{ Sterile } & \multicolumn{4}{|c|}{ SRB-Inoculated } \\
\hline & \multirow{2}{*}{$\begin{array}{c}R_{\mathrm{s}} \\
\left(\Omega \cdot \mathrm{cm}^{2}\right)\end{array}$} & \multicolumn{2}{|c|}{$Q_{\mathrm{dl}}$} & \multirow{2}{*}{$\begin{array}{c}R_{\mathrm{ct}} \\
\left(\Omega \cdot \mathrm{cm}^{2}\right)\end{array}$} & \multirow{2}{*}{$\begin{array}{c}R_{\mathrm{s}} \\
\left(\Omega \cdot \mathrm{cm}^{2}\right)\end{array}$} & \multicolumn{2}{|l|}{$Q_{\mathrm{dl}}$} & \multirow{2}{*}{$\begin{array}{c}R_{\mathrm{ct}} \\
\left(\Omega \cdot \mathrm{cm}^{2}\right)\end{array}$} \\
\hline & & $Y_{0} / \mathrm{S} \mathrm{s}^{n} \cdot \mathrm{cm}^{-2}$ & $n$ & & & $Y_{0} / \mathrm{S} \mathrm{s}^{n} \cdot \mathrm{cm}^{-2}$ & $n$ & \\
\hline 1 & 137.2 & $1.017 \times 10^{-4}$ & 0.913 & 9318 & 129.8 & $4.862 \times 10^{-4}$ & 0.791 & 13,950 \\
\hline 4 & 137.7 & $1.423 \times 10^{-4}$ & 0.903 & 6754 & 126.7 & $9.03 \times 10^{-4}$ & 0.902 & 10,810 \\
\hline 7 & 101.3 & $2.964 \times 10^{-4}$ & 0.786 & 6699 & 110.1 & $3.173 \times 10^{-4}$ & 0.866 & 3836 \\
\hline 10 & 217.4 & $1.582 \times 10^{-4}$ & 0.789 & 5533 & 146 & $1.782 \times 10^{-4}$ & 0.81 & 2678 \\
\hline 14 & 147.3 & $1.425 \times 10^{-4}$ & 0.851 & 4640 & 190.9 & $2.409 \times 10^{-4}$ & 0.746 & 1467 \\
\hline
\end{tabular}

\section{Discussion}

In the soils, the corrosion of steel was governed by the electrochemical activation reaction. Research $[27,39,40]$ has shown that the anodic process of corrosion of X80 steel is the dissolution of Fe (Equation (2)), and the cathodic reaction of corrosion is mainly the depolarization of $\mathrm{H}^{+}$(Equation (3)):

Anodic reaction (metal dissolution):

$$
\mathrm{Fe}^{0} \rightarrow \mathrm{Fe}^{2+}+2 \mathrm{e}
$$

Cathode reaction:

$$
2 \mathrm{H}^{+}+2 \mathrm{e} \rightarrow \mathrm{H}_{2}
$$

Total reaction:

$$
\mathrm{Fe}^{0}+2 \mathrm{H}^{+} \rightarrow \mathrm{Fe}^{2+}+\mathrm{H}_{2}
$$

In the presence of SRB, the mechanism model of the electrochemical reactions is presented in Figure 10. SRB can shuttle electrons from extracellular iron oxidation across the cell wall to reach the cytoplasm where sulfate reduction occurs under biocatalysis [22]. Sessile SRB cells under an SRB biofilm harvest energy from the reduction of $\mathrm{SO}_{4}{ }^{2-}$ for metabolic activities [41]. Therefore, $\mathrm{SO}_{4}{ }^{2-}$ ions were reduced by SRB to HS ${ }^{-}$ ions (Equation (5)). $\mathrm{Fe}^{2+}$ ions generated by the anodic process further reacted with $\mathrm{HS}^{-}$ based on Equation (6).

Sulfate reduction by SRB:

$$
\begin{gathered}
\mathrm{SO}_{4}{ }^{2-}+9 \mathrm{H}^{+}+8 \mathrm{e} \rightarrow \mathrm{HS}^{-}+4 \mathrm{H}_{2} \mathrm{O} \\
\mathrm{Fe}^{2+}+\mathrm{HS}^{-} \rightarrow \mathrm{FeS}+\mathrm{H}^{+}
\end{gathered}
$$

FeS is considered the typical corrosion product when steels are exposed to an SRBcontaining environment [42]. The accumulation of iron sulfide at the early stage may have protective effects. However, sulfide films are unstable [43], and the protective ability 
of the films can be degraded by bacteria's metabolic actions. Hence, galvanic couple active corrosion cells occur between the sulfide and the exposed matrix (anode), further accelerating the corrosion rate significantly. The reduced sulfur compounds (ferrous sulfide) thus enhance localized corrosion by inducing pitting corrosion. Furthermore, some cations, e.g., $\mathrm{H}^{+}$, are caged beneath the biofilm and corrosion product due to the anion selectivity of the biofilm, which cause acidification underneath the biofilm, further leading to severe pitting corrosion.

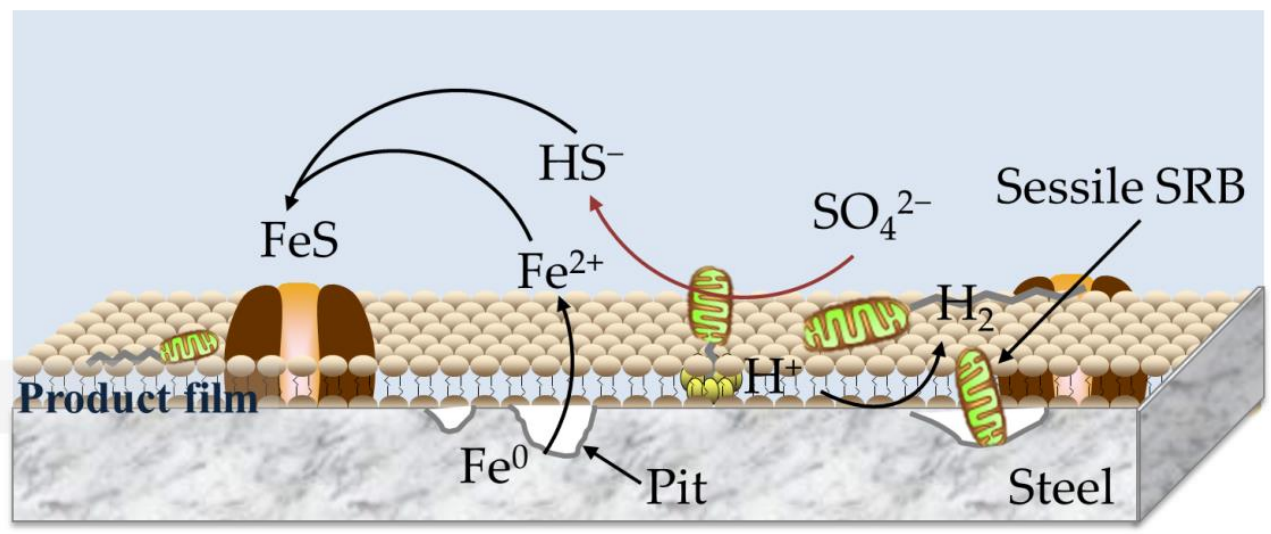

Figure 10. Mechanism model to illustrate the SRB corrosion process of X80 steel.

In addition, EIS testing can provide insights into corrosion kinetic parameters by reflecting the electrochemical characteristics of a corrosion system [44,45]. Figure 11 shows the variation in $1 / R_{\mathrm{ct}}$ values as a function of time. In general, at high frequencies, the resistance of the steel is related to the solution resistance $\left(R_{\mathrm{S}}\right)$, while that at low frequencies is relative to the charge transfer resistance $\left(R_{\mathrm{ct}}\right)$, which is inversely proportional to the corrosion current density and reflects the corrosion rate of steel. As shown in Figure 11, the $R_{\mathrm{ct}}$ of the specimen in the presence of SRB is lower than that in the abiotic solution in the first 4 days, which indicates that the corrosion of steel is inhibited in the first 4 days of testing in the presence of SRB. This inhibition is relevant to the iron sulfide and the activity of the SRB biofilm. The inhibition effect is attributed to the living cells. In the presence of SRB, the SRB biofilm layer on the specimen surface with FeS particles, which can be an obstacle to the migration of ions, e.g., $\mathrm{SO}_{4}{ }^{2-}$, into the interface of the metal, further decreases the corrosion of steel [28]. Moreover, it is well known that the SRB biofilm, with negative charges, is highly bioactive in the early stage of this experiment, which also has a repulsion effect on corrosive ions. However, with the increase in the immersion time, the activity of the biofilm would decrease. Therefore, the corrosion rate continues to increase rapidly in the inoculated condition and shows a higher value compared to that in the abiotic solution. The above results show that SRB activities have a significant effect on the corrosion of steel. Steel corrosion is inhibited by the highly bioactive SRB biofilm at the early stage of the experiment, while SRB can accelerate corrosion at the later stage of the experiment. 


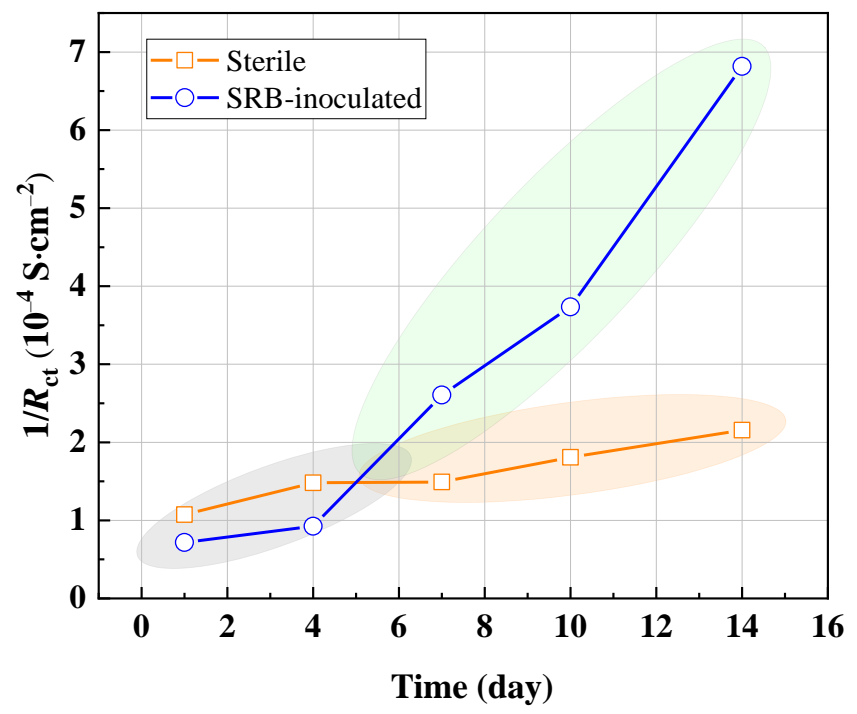

Figure 11. $1 / R_{\mathrm{ct}}$ value of specimen in the abiotic and inoculated soil solutions as a function of time.

\section{Conclusion}

The effect of SRB on the corrosion of X80 steel was investigated in an SRB-containing soil solution. The conclusions are provided below:

(1) The biofilm distributed on the specimen surface, and the biofilm thickness was $20 \mu \mathrm{m}$ after 14 days.

(2) Both the SRB activity and metabolite significantly affect the corrosion behavior of X80 steel. SRB can form a biofilm on the steel surface in the inoculated soil solution and play a vital role in the corrosion of X80 steel.

(3) EIS results indicate that the corrosion of steel is inhibited by the activity of SRB in the first 4 days and enhanced in the rest of the experiment.

(4) Localized corrosion dominates in the soil solution, and pitting corrosion of steel is severe in the inoculated soil solution.

Author Contributions: Conceptualization, L.C.; methodology, L.C.; software, L.C.; validation, L.C., B.W. and X.X.; formal analysis, L.C.; investigation, L.C.; resources, L.C.; data curation, L.C.; writingoriginal draft preparation, L.C.; writing-review and editing, L.C. and B.W.; visualization, X.X.; supervision, X.X.; project administration, L.C.; funding acquisition, L.C. and B.W. All authors have read and agreed to the published version of the manuscript.

Funding: We are grateful for the financial supported by the National Natural Science Foundation of China (No. 51966017) and the Teaching Reform Project of Xinjiang (XJJG201911).

Institutional Review Board Statement: Not applicable.

Informed Consent Statement: Not applicable.

Data Availability Statement: The data presented in this study are available on request from the corresponding author.

Conflicts of Interest: The authors declare no conflict of interest.

\section{References}

1. Feng, Y.; Cheng, Y.F. An intelligent coating doped with inhibitor-encapsulated nanocontainers for corrosion protection of pipeline steel. Chem. Eng. J. 2017, 315, 537-551. [CrossRef]

2. Wei, B.X.; Pang, J.Y.; Xu, J.; Sun, C.; Zhang, H.W.; Wang, Z.Y.; Ke, W. Microbiologically influenced corrosion of TiZrNb medium-entropy alloys by Desulfovibrio desulfuricans. J. Alloys Compd. 2021, 875, 160020. [CrossRef]

3. Xu, D.K.; Huang, W.; Ruschau, G.; Hornemann, J.; Wen, J.; Gu, T.Y. Laboratory investigation of MIC threat due to hydrotest using untreated seawater and subsequent exposure to pipeline fluids with and without SRB spiking. Eng. Fail. Anal. 2013, 28, 149-159. [CrossRef] 
4. Starosvetsky, J.; Starosvetsky, D.; Armon, R. Identification of microbiologically influenced corrosion (MIC) in industrial equipment failures. Eng. Fail. Anal. 2007, 14, 1500-1511. [CrossRef]

5. Hou, B.R. The Cost of Corrosion in China; Science Press: Beijing, China, 2019.

6. Huang, L.Y.; Huang, Y.; Lou, Y.T.; Qian, H.C.; Xu, D.K.; Ma, L.W.; Jiang, C.Y.; Zhang, D.W. Pyocyanin-modifying genes phzM and phzS regulated the extracellular electron transfer in microbiologically-influenced corrosion of X80 carbon steel by Pseudomonas aeruginosa. Corros. Sci. 2020, 164, 108355. [CrossRef]

7. Brooks, W. Microbiologically-influenced corrosion Riviera Park case study. In Corrosion; NACE International: Houston, TX, USA, 2013.

8. Tambe, S.P.; Jagtap, S.D.; Chaurasiya, A.K.; Joshi, K.K. Evaluation of microbial corrosion of epoxy coating by using sulphate reducing bacteria. Prog. Org. Coat. 2016, 94, 49-55. [CrossRef]

9. Sarioğlu, F.; Javaherdashti, R.; Aksöz, N. Corrosion of a drilling pipe steel in an environment containing sulphate-reducing bacteria. Int. J. Pres. Ves. Pip. 1997, 73, 127-131. [CrossRef]

10. Bhat, S.; Sharma, V.K.; Thomas, S.; Anto, P.F.; Singh, S.K. 8-in pipeline from group gathering station to Central Tank Farm. Mater Perform. 2011, 50, 50-53.

11. Abedi, S.S.; Abdolmaleki, A.; Adibi, N. Failure analysis of SCC and SRB induced cracking of a transmission oil products pipeline. Eng. Fail. Anal. 2007, 14, 250-261.

12. Liu, H.W.; Cheng, Y.F. Mechanistic aspects of microbially influenced corrosion of X52 pipeline steel in a thin layer of soil solution containing sulphate-reducing bacteria under various gassing conditions. Corros. Sci. 2018, 133, 178-189. [CrossRef]

13. Xu, J.; Wang, K.X.; Sun, C.; Wang, F.H.; Li, X.M.; Yang, J.; Yu, C.K. The effects of sulfate reducing bacteria on corrosion of carbon steel Q235 under simulated disbonded coating by using electrochemical impedance spectroscopy. Corros. Sci. 2011, 53, 1554-1562. [CrossRef]

14. Wei, B.X.; Xu, J.; Fu, Q.; Qin, Q.Y.; Bai, Y.L.; Sun, C.; Wang, C.; Wang, Z.Y.; Ke, W. Effect of sulfate-reducing bacteria on corrosion of X80 pipeline steel under disbonded coating in a red soil solution. J. Mater. Sci. Technol. 2021, 87, 1-17. [CrossRef]

15. Von Wolzogen Khur, C.A.H.; van der Vlugt, L.S. De grafiteering van gietijzeralselectro biochemichproces in anaerobe Gronden. Water 1934, 18, 147-165.

16. AlAbbas, F.M.; Bhola, R.; Spear, J.R.; Olson, D.L.; Mishra, B. Electrochemical characterization of microbiologically influenced corrosion on linepipe steel exposed to facultative anaerobic Desulfovibrio sp. Int. J. Electrochem. Sci. 2013, 8, 859-871.

17. Venzlaff, H.; Enning, D.; Srinivasan, J.; Mayrhofer, K.J.J.; Hassel, A.W.; Widdel, F.; Stratmann, M. Accelerated cathodic reaction in microbial corrosion of iron due to direct electron uptake by sulfate-reducing bacteria. Corros. Sci. 2013, 66, 88-96. [CrossRef]

18. Iverson, W.P. Biological corrosion. In Advances in Corrosion Science and Technology; Fontana, M.G., Staehle, R.W., Eds.; Springer: Boston, MA, USA, 1972; pp. 1-42.

19. Dong, Z.H.; Liu, T.; Liu, H.F. Influence of EPS isolated from thermophilic sulphate-reducing bacteria on carbon steel corrosion. Biofouling 2011, 27, 487-495. [CrossRef]

20. Videla, H.A.; Herrera, L.K. Understanding microbial inhibition of corrosion. A comprehensive overview. Int. Biodeterior. Biodegrad. 2009, 63, 896-900. [CrossRef]

21. ZDong, H.; Shi, W.; Ruan, H.M.; Zhang, G.A. Heterogeneous corrosion of mild steel under SRB-biofilm characterised by electrochemical mapping technique. Corros. Sci. 2011, 53, 2978-2987.

22. Gu, T.Y.; Jia, R.; Unsal, T.; Xu, D.K. Toward a better understanding of microbiologically influenced corrosion caused by sulfate reducing bacteria. J. Mater. Sci. Technol. 2019, 35, 631-636. [CrossRef]

23. $\mathrm{Xu}, \mathrm{D} . \mathrm{K} . ; \mathrm{Gu}, \mathrm{T}$. Carbon source starvation triggered more aggressive corrosion against carbon steel by the Desulfovibrio vulgaris biofilm. Int. Biodeterior. Biodegrad. 2014, 91, 74-81. [CrossRef]

24. Liu, H.W.; Cheng, Y.F. Mechanism of microbiologically influenced corrosion of X52 pipeline steel in a wet soil containing sulfate-reduced bacteria. Electrochim. Acta 2017, 253, 368-378. [CrossRef]

25. Daia, M.J.; Liu, J.; Huang, F.; Zhang, Y.H.; Cheng, Y.F. Effect of cathodic protection potential fluctuations on pitting corrosion of X100 pipeline steel in acidic soil environment. Corros. Sci. 2018, 143, 428-437. [CrossRef]

26. Yan, M.C.; Sun, C.; Xu, J.; Ke, W. Anoxic corrosion behavior of pipeline steel in acidic soils. Ind. Eng. Chem. Res. 2014, 53, 17615-17624. [CrossRef]

27. Yan, M.C.; Sun, C.; Xu, J.; Dong, J.H.; Ke, W. Role of Fe oxides in corrosion of pipeline steel in a red clay soil. Corros. Sci. 2014, 80, 309-317. [CrossRef]

28. Wei, B.X.; Qin, Q.Y.; Fu, Q.; Bai, Y.L.; Xu, J.; Yu, C.; Sun, C.; Ke, W. X80 steel corrosion induced by alternating current in water-saturated acidic soil. Corrosion 2020, 76, 248-267. [CrossRef]

29. Sun, C.; Xu, J.; Wang, F.H.; Yu, C.K. Effect of sulfate reducing bacteria on corrosion of stainless steel 1Cr18Ni9Ti in soils containing chloride ions. Mater Chem. Phys. 2011, 126, 330-336. [CrossRef]

30. Wu, T.Q.; Yan, M.C.; Yu, L.B.; Zhao, H.; Sun, C.; Yin, F.C.; Ke, W. Stress corrosion of pipeline steel under disbonded coating in a SRB-containing environment. Corros. Sci. 2019, 157, 518-530. [CrossRef]

31. Liu, H.W.; Xu, D.; Yang, K.; Liu, H.F.; Cheng, Y.F. Corrosion of antibacterial Cu-bearing 316L stainless steels in the presence of sulfate reducing bacteria. Corros. Sci. 2018, 132, 46-55. [CrossRef]

32. Zhou, E.Z.; Li, H.; Yang, C.; Wang, J.; Xu, D.K.; Zhang, D.W.; Gu, T.Y. Accelerated corrosion of 2304 duplex stainless steel by marine Pseudomonas aeruginosa biofilm. Int. Biodeterior. Biodegrad. 2018, 127, 1-9. [CrossRef] 
33. Wu, T.Q.; Jin, X.; Yan, M.C.; Cheng, S.; Yu, C.K.; Wei, K. Synergistic effect of sulfate-reducing bacteria and elastic stress on corrosion of $X 80$ steel in soil solution. Corros. Sci. 2014, 83, 38-47. [CrossRef]

34. Tan, B.J.; Klabunde, K.J.; Sherwood, P.M.A. X-ray photoelectron spectroscopy studies of solvated metal atom dispersed catalysts. Monometallic iron and bimetallic iron-cobalt particles on alumina. Chem. Mater. 1990, 2, 186-191. [CrossRef]

35. Zheng, B.; Li, K.; Liu, H.; Gu, T. Effects of magnetic fields on microbiologically influenced corrosion of 304 stainless steel. Ind. Eng. Chem. Res. 2013, 53, 48-54. [CrossRef]

36. Li, Y.; Feng, S.; Liu, H.; Tian, X.; Xia, Y.; Li, M.; Xu, K.; Yu, H.; Liu, Q.; Chen, C. Bacterial distribution in SRB biofilm affects MIC pitting of carbon steel studied using FIB-SEM. Corros. Sci. 2020, 167, 108512. [CrossRef]

37. Zuo, R.; Kus, E.; Mansfeld, F.; Wood, T.K. The importance of live biofilms in corrosion protection. Corros. Sci. 2005, 47, 279-287. [CrossRef]

38. Michael, D.W. Bacterial adhesion: Seen any good biofilms lately? Clin. Microbiol. Rev. 2002, 15, 155-166.

39. Yan, M.C.; Sun, C.; Xu, J.; Wu, T.Q.; Yang, S.; Ke, W. Stress corrosion of pipeline steel under occluded coating disbondment in a red soil environment. Corros. Sci. 2015, 93, 27-38. [CrossRef]

40. Xu, R.; Zhao, A.; Li, Q.; Kong, X.; Ji, G. Acidity regime of the red soils in a subtropical region of southern China under field conditions. Geoderma 2003, 115, 75-84. [CrossRef]

41. Li, H.W.; Dake, X.K.; Yingchao, L.; Hao, F.; Zhiyong, L.; Xiaogang, L.; Tingyue, G.; Ke, Y.; Zhang, W. Extracellular electron transfer is a bottleneck in the microbiologically influenced corrosion of C1018 carbon steel by the biofilm of sulfate-reducing bacterium Desulfovibrio vulgaris. PLoS ONE 2015, 10, e0136183.

42. Fatah, M.C.; Ismail, M.C.; Wahjoedi, B.A. Effects of sulphide ion on corrosion behaviour of X52 steel in simulated solution containing metabolic products species: A study pertaining to microbiologically influenced corrosion (MIC). Corros. Eng. Sci. Techn. 2013, 48, 211-220. [CrossRef]

43. Castaneda, H.; Benetton, X.D. SRB-biofilm influence in active corrosion sites formed at the steel-electrolyte interface when exposed to artificial seawater conditions. Corros. Sci. 2008, 50, 1169-1183. [CrossRef]

44. Wei, B.X.; Qin, Q.Y.; Bai, Y.L.; Yu, C.K.; Xu, J.; Sun, C.; Ke, W. Short-period corrosion of X80 pipeline steel induced by AC current in acidic red soil. Eng. Fail. Anal. 2019, 105, 156-175. [CrossRef]

45. Wu, T.Q.; Yan, M.C.; Zeng, D.C.; Xu, J.; Yu, C.K.; Sun, C.; Ke, W. Microbiologically induced corrosion of X80 pipeline steel in a near-neutral pH soil solution. Acta. Metall. Sin. Engl. 2014, 28, 93-102. [CrossRef] 